\title{
Science and the Conservation of Food*
}

\section{Agencies Affecting Foods}

$\mathrm{T}$ HERE are many agencies, biological, chemical and physical, which may affect foodstuffs, either by spoiling their appearance or rendering them unfit for consumption. Bacteria are most important among the biological factors, but yeasts and moulds, which may either aid or hinder preservation, have also to be considered; and then there are such animal pests as sugar- and cheese-mites, moths, rats and beetles, all of which may damage the raw material used in food manufacture, or attack the finished products.

Food products have also to be protected from heat, dampness, the oxygen of the air and sometimes from light as well. These last two factors, acting in association, produce the bleaching or discoloration which is sometimes seen in bottled fruit, when pieces of the fruit project beyond the syrup into the space at the top of the bottle. Then again, canned food must be protected from the action of acids and salts which might corrode the tin.

There are also substances contained in the foodstuffs themselves which may have a destructive action, namely, the enzymes. These are present in both vegetable and animal cells, but they can exist independently of them. One enzyme having an important bearing on food preservation in connexion with jam-making is pectase, which, if it is allowed to do so, will destroy the pectin which is responsible for the 'setting' property of jam. Jams, in fact, present a number of problems to the manufacturer, and the way he has been helped to solve these is a good example of the assistance which science has rendered to industry.

\section{JAMS}

Substances of importance for the keeping quality of jam are held in solution in the water it contains, for example, sugar, acids and salts. The osmotic pressure of these substances, the sugar in particular, can be responsible for protecting the jam from the growth of moulds, because, for germination, a mould spore must first absorb water. If the osmotic pressure of the jam is equal to or greater than that of any spore which falls upon it, either no water will pass from the jam to the spore or the spore will lose water and so dry up and eventually die, and in both these cases its further development will be arrested. The British Food Manufacturers' Research Association has actually determined the minimum percentage of solids necessary to bring about this condition.

There is, however, still a risk of moulds developing in a jam if the relative humidity of the atmosphere to which it is exposed is above 82 per cent.. Then the jam will absorb moisture and so its osmotic pressure becomes lower than that of the mould spores.

Another defect frequently arising in jams is crystallization or granulation of the sugar. In the jam-making process, sucrose is inverted by the boiling acid, and it is necessary that just the right degree

- Substance of a Friday evening discourse delivered at the Royal Institution on April 16, by Mr. T. Macara, director of research of the British Food Manufacturers' Research Association. of inversion should take place if no crystallization is to occur. Thus, if the sugar is under-inverted too much sucrose is left and this crystallizes out. If, on the other hand, it is over-inverted, too much dextrose is formed and this crystallizes out. As fruits vary very much in the amount of acid they contain, the manufacturer must be able to discover the degree of inversion taking place, and modify his process accordingly.

The setting property of jam has already been mentioned, and it is important to remember that unless jam is properly set it cannot be transported and handled. It is therefore necessary to make use of the pectin naturally occurring in fruit cells. Pectin is a complex of different substances, and therefore its properties vary from one fruit to another; for this reason the setting properties of some fruit juices are superior to those of others, for example, gooseberry, red currant and apple are good, while strawberry is poor. Now, pectin must be protected from the naturally occurring enzyme, pectase, which destroys it. So long as the cell structure remains intact, the pectase does not attack the pectin, but in fruit which has become damaged by bruising, the pectase appears to get out of control, and in the case of raspberries all the pectin may disappear in twelve hours. In this fact lies the justification for manufacturers using "added fruit juice" or "pectin" in the making of jam.

Pectin may also lose its jellifying powers by the action of prolonged heat. It is therefore necessary to eliminate any over-heating in the manufacturing process, and this is not always easy when large quantities of liquid have to be dealt with.

\section{Meat Products}

The processes of jam-making are more familiar to the public than those of meat preservation. An important difference to bear in mind is that meat has no natural acids to assist the preservation process. Meat, if it is to be kept, must be protected from putrefactive bacteria, which though harmless in them. selves feed upon animal and vegetable debris, gradually converting them into ammonia and carbon dioxide, etc.

Refrigeration deprives the bacteria of water which is necessary for their growth, the water in the meat tissues being converted into ice. The bacteria are not necessarily killed, but their development is inhibited. Some of the bacteria can grow at temperatures around freezing point, and for this reason chilled meat cannot be kept so long as meat which is frozen at temperatures well below freezing point. The growth of bacteria can also be restrained by certain concentrations of carbon dioxide in the air.

Although the spores of some bacteria are highly resistant to heat, it has been possible to use heat sterilization as a method for meat preservation. It is, of course, necessary for the manufacturer to know the combinations of time and temperature at which all spores likely to be present will be destroyed. 
Allowance must be made, when the product is packed in a tin, for the penetration of heat to the deepest parts of the package; and the rate of penetration will vary considerably with the density of the contents, being much slower for meat than for a tin of fluid.

\section{Food PoIsoning}

A product canned by correct processes is one of the safest articles of diet it is possible to have, and many complaints made to manufacturers that their products have caused illness, have shown on investigation to have no justification. According to Prof. Tanner of Illinois (speaking at the Congress of Microbiology, 1936), in the past canners and distributors have tried to avoid publicity by settling their claims out of court. Medical practitioners are often un. familiar with the procedures necessary to establish definitely the causative factors in food poisoning. There is also much prejudice on the part of the public as well as ignorance of the great care generally taken in the manufacture of these products. It has been shown in Great Britain and the United States that by far the largest number of cases of food poisoning are caused by foods which have been prepared in the home or by products sold in a pre-cooked condition, but not sterilized.

\section{Tinplate Containers}

A difficulty, still not completely solved, is that of producing in commercial quantities the perfect tinplate for the construction of a can, or tin stopper for a glass jar. Then also, the machinery necessary in making the can may break the tin coating and expose the base metal, iron. The iron thus exposed may be attacked by the salt present in meat and vegetable products. An attempt has been made to produce a lacquer which when applied to the tinplate would prevent this action. Several difficulties have so far prevented the realization of this ideal.

\section{Preservation of Meat}

The preservation of meat by means of salts has long been practised, but only recently have its scientific principles been studied. The production of colour as well as preservation from putrefaction is brought about by the use of saltpetre. Bacterial action converts the nitrate of the saltpetre into nitrite, which combines with hæmoglobin, and when the meat is boiled the latter is converted into nitrohæmochromogen, which has the bright red colour characteristic of properly cured silverside. The micrococci responsible for this action can grow in media containing as much as 20 per cent of salt, in which concentrations the putrefactive bacteria cannot exist. Nor can their spores develop in media containing as much as 10 per cent of salt.

\section{Chocolate and Confectionery}

Changes in atmospheric temperature and humidity are liable to produce changes in chocolate and confectionery. The British Food Manufacturers' Research Association has given manufacturers a great deal of help in determining the conditions necessary for the production and storage of satisfactory chocolate. In the factory, it is generally possible to secure these conditions, but in retail premises it is not so easy. If the manufacturer were able to deliver his goods direct from his warehouse to the consumer, defective products would not be so commonly seen as they are at the present time.

\section{Conduction of Electricity in Solids}

\section{Conference at Bristol}

\begin{abstract}
A CONFERENCE on the "Conduction of Electricity in Solids" was held at Bristol on July 13-16 under the joint auspices of the Physical Society and the University of Bristol. The discussions were opened by R. W. Pohl, who gave an account of the fundamental work on electron conductivity and photochemical processes in alkali-halide crystals carried out in his laboratory at Göttingen. The paper was mainly concerned with the properties of crystals which have been coloured either by heating in alkali vapour or in other ways, introducing colour centres called ' $F$ 'centres'. A discussion followed on the exact nature of these $F$-centres, and, although there is as yet no certainty on this point, a hypothesis was proposed which seemed to have a good deal to recommend it, namely that an $F$-centre is an electron localized at a point in the lattice where a negative ion is missing.

Papers on phosphorescence in halide and sulphide crystals were given by R. Hilsch (Göttingen) and J. T. Randall (General Electrical Co., Ltd.) who discussed to what extent this phenomenon is related
\end{abstract}

to photoconductivity and to the transference of an electron to a large distance from the phosphorescent centre.

J. H. de Boer (Eindhoven) gave a paper by himself and E. J. W. Verwey on semi-conductors with partially filled $3 d$-bands. He pointed out that the electron theory of metals in its present form is not applicable to a substance such as nickel monoxide, in which a 'band' of electron states is incompletely filled, and therefore ought to behave like a metallic conductor, but which has in fact a resistance some $10^{9}$ times greater than a metal. Both he and $\mathrm{R}$. Peierls gave indications of the way in which the theory would have to be modified to include these substances.

Subsequent papers dealt with conduction in metals. G. Borelius gave an account of the work carried out at his Institute in Stockholm on the resistance of alloys, and especially of alloys in which the atoms can take up an ordered or disordered arrangement. His own pioneer work on the treatment of this prob. lem from the point of view of thermodynamics 